\title{
ASO Visual Abstract: SLC7A9 as a Potential Biomarker for Lymph Node Metastasis of Esophageal Squamous Cell Carcinoma
}

Hayato Baba, $\mathrm{MD}^{1,2}$, Mitsuro Kanda, MD, PhD, FACS ${ }^{2}$, Koichi Sawaki, MD, PhD $^{2}$, Shunsuke Nakamura, MD, $\mathrm{PhD}^{2}$, Sei Ueda, $\mathrm{MD}^{2,3,4}$, Dai Shimizu, MD, $\mathrm{PhD}^{2}$, Masahiko Koike, MD, $\mathrm{PhD}^{2}$, Yasuhiro Kodera, MD, PhD, FACS ${ }^{2}$, and Tsutomu Fujii, MD, PhD, FACS ${ }^{1}$

${ }^{1}$ Department of Surgery and Science, Faculty of Medicine, Academic Assembly, University of Toyama, Toyama, Japan; ${ }^{2}$ Department of Gastroenterological Surgery, Nagoya University Graduate School of Medicine, Nagoya, Japan;

${ }^{3}$ Department of Maxillofacial Surgery, School of Dentistry, Aichi-gakuin University Graduate School of Medicine, Nagoya, Japan; ${ }^{4}$ Department of Surgery, School of Dentistry, Aichi-gakuin University Graduate School of Medicine, Nagoya, Japan

The authors first showed the potential role of solute carrier family 7, member 9 (SLC7A9) as an oncogene in esophageal squamous cell carcinoma (ESCC). Tumor
SLC7A9 expression may serve as a prognostic marker for lymph node metastasis in ESCC patients (https://doi.org/ 10.1245/s10434-021-11001-1).

\section{SLC7A9; Potential Therapeutic Target and Novel Biomarker for Esophageal Squamous Cell Carcinoma}

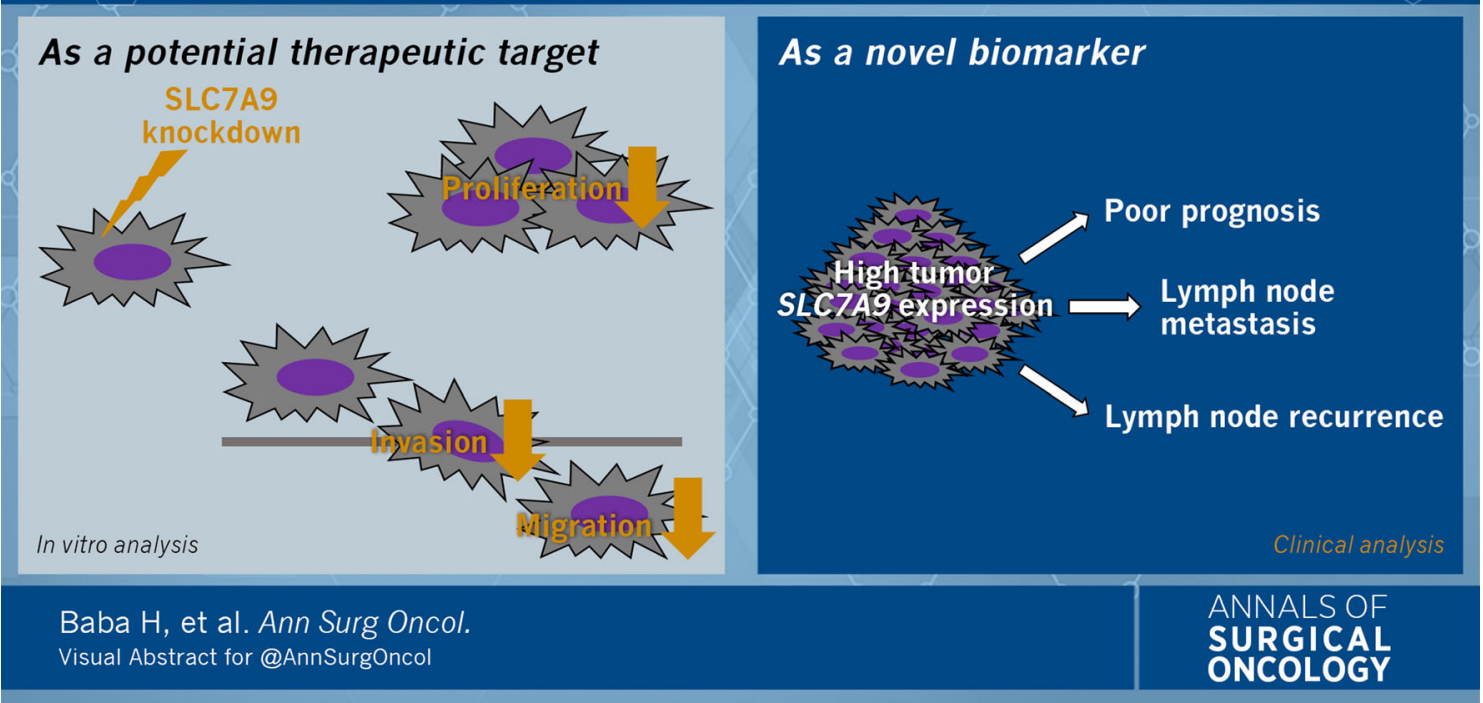

(C) Society of Surgical Oncology 2021

M. Kanda, MD, PhD, FACS

e-mail: m-kanda@med.nagoya-u.ac.jp
DISCLOSURE None.

Publisher's Note Springer Nature remains neutral with regard to jurisdictional claims in published maps and institutional affiliations. 